\title{
What's in a Name?
}

\section{Why it is of vital importance to get the pronunciation right?}

That which we call a rose by any other name would smell as sweet.

\begin{abstract}
Health services across the world are on the one hand the most regulated of all professions, the workforce planning is the most advanced and the restrictions on licence to practice most stringent, especially across borders- yet the workforce is dependent on the ability of large scale movement of professionals across nation-states. The UK NHS has over $41 \%$ of its doctors and a quarter of all nurses who were born / trained overseas. This is not much different to many other advanced health systems.

It is also recognised that patient outcomes, recruitment and retention of healthcare professionals who are in great demand depends on autonomy, job satisfaction and a sense of value, equality and a just environment.
\end{abstract}

A fundamental tenet of equality, celebrating diversity and inclusion is how organisation or society deals with the immigrant professionals or 'foreigners'. The ability to correctly pronounce 'foreign' names is one of the fundamental and most obvious demonstration of respect one accords to a fellow human.

There is a long standing practice of transfiguring foreign sounding names to anglicised or westernized versions for ease of use. The westernization of foreign names is predominantly imposed by the dominant segments of populations on those considered inferior. There is clear evidence of social inequalities linked to one's race, ethnicity, immigration and gender. Transfiguring one's name is a clear example of such discrimination, microaggression and a form of bias. It is time that we understood the impact of such microaggressions of colleagues and our patients. It should be vital for all professionals to take the time and attention needed to get the pronunciation right and in the process understand the cultural diversity, identity and demonstrate due respect and equality. It is also imperative on those of us with foreign sounding names that we help colleagues navigate the rich heritage of our culture and identity and do so with humility. It can only then be a win-win for all.

Keywords; microaggressions; mispronunciation of names; foreigners
Indranil Chakravorty $\mathrm{PhD}$ FRCP

St Georges University Hospital, London

indranil.chakravorty@stgeorges.nhs. $\underline{\mathrm{uk}}$

Cite as; Chakravorty, I. (2021) Editorial; What's in a name? Why it is important that we get the pronunciation right? Sushruta J Health Pol \& Opin Vol 14: Issue 2: p13 ePub 15 Aug 2021 DOI: https://doi.org/10.38192/14.2.12

Article Information

Submitted 14.8.21

Published 15.8.21

ISSN 2732-5164 (Online)

ISSN 2732-5156 (Print)

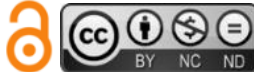

scienceOPEN.com 
William Shakespeare is probably to be blamed for the fundamental adage the reduces the need for people to remember or as in the case of the hospital in South West England that encouraged staff with 'foreign sounding' or 'difficult' names to choose 'Westernised' versions so that it would be easier for others to refer to them. This little storm in a tea cup controversy may have passed many of us by if one were not glued to the twitter sphere. Bod Goddard, President of the Royal College of Physicians referred to this in his bulletin to members and fellows of RCP London as 'this behaviour is unacceptable and must be called out'. (RCP Members Bulletin, 9 Aug 2021) I remember the MRCP diploma award ceremony where the Registrar reads every name with due care and attention. Perhaps the only time as an immigrant doctor one heard one's name pronounced correctly. The HSJ reported that 'Hospital line managers allegedly told staff from minority ethnic backgrounds to adopt 'Western work names' because their own were deemed 'too difficult' to pronounce, according to Care Quality Commission inspectors' [1] while inspecting the University Hospitals Bristol and Weston NHS Trust.[2]

Why is this issue important?

One's name is a vital ingredient of one's identity and persona. Names are perhaps the second most common feature one notices about an individual immediately after their countenance at the first encounter. Even in non-visual communication, the name features immediately after one notices one's voice. Other attributes such as gender, colour and race usually come after. Names help to consolidate uniqueness and help to distinguish one from others. We humans are social animals, and society depends on interactions which then lead to relationships. Every interaction begins with a name. John F Kennedy (President of the United States 1961-63) was clear in the importance of the name when he reiterated that 'you may forgive your enemies but never forget their names'. So the importance of the name also applies not just to your friends but foes, too.

Naming reflects society and culture

Names have been transformed, transfigured and often modified beyond recognition for convenience. Yet the care we take to get names right is a topic increasingly under scrutiny as Kamala Harris took office in the US. Harris, the first female, black and Asian American to serve as US vice-president, has faced consistent mispronunciations of her name. In some cases, they present as apparently wilful errors used to suggest 'otherness', or draw attention to her ethnicity. Harris has made a point of correcting mispronunciations accurately, sending an important signal that there's no excuse for failing to master names - and serving as a role model for those who want to reclaim their identities.

But there is an uncomfortable truth here. There is a power gradient that determines whose name is transformed. In many countries, the rulers have determined what the indigenous names will be transformed to. After four centuries of imperial dominance rule in India, it took almost five decades before the anglicised names of states and cities were changed back to (some semblance) of their original indigenous ones. The transformation names of people are not much different but they cannot be altered, without losing one's identity in the process.

The changing of people's names has a racialised history, the renaming during slavery, the renaming or Americanization of Latino and indigenous communities for schools - practice directly linked to racism and inferiority of race.[3] This history is indeed painful even though it seems so far in the past, and is not removed for many AfricanAmericans, many of whom don't know their ancestors' names and carry the names of their previous slave owners.

As the world has moved from an imperial form of domination to a more corporate variety, the scenario has changed, but the outcomes are still the same. Immigrants from economically or politically weaker countries who contribute to migration tend to have to transform their names to fit acceptable norms of the more dominant nation-states. Classical examples are of people from China, Hong Kong, Vietnam and Philippines who may have to adopt a 'western' name when they come to study or work in the Western hemisphere. Such practices are so widespread that rarely does anyone think of questioning or challenging this practice.

Then there is a variety in the norms of nomenclature. Instead of personal criteria, specific 
rules for naming a child are more prevalent in, for example, Asian societies. These rules can be related to facts such as the totems and family trees, the date and time of birth, or events that happened during or after pregnancy. For centuries modifications of (difficult to pronounce) names have become the accepted norm across the world. In many cultures, the naming is based on a given name, a parental name (usually of a male parent) and either a village/ place/tribal name. Whereas the norm in the western hemisphere is of a surname/ family name and a given name. Many people making a cross-cultural transition struggle to fit their names into the surname/middle name/ Given name boxes. Any such transformation or transfiguration takes away chunks from one's identity.

This article will not do justice to religious norms, transformation based on missionary influence nor do we have the moral right to discuss the practice of women having to change their family name to one of the (usually male) partners'. A practice, which needs to be stopped forever, and will happen once there is true gender equality.

\section{Mispronouncing a form of microaggression}

Microaggressions are instances of subtle and indirect racism against marginalised populations. Under this umbrella, name-based microaggressions constitute a specific category that capture the subtle discriminatory comments that minority individuals experience when interacting with others given their first and last names of ethnic origin. Names are prominent identifiers that can often tell the story of one's ethnicity, cultural background, and familial lineage. In Western societies, perhaps not unexpectedly, there is a tendency for White European names and whiteness in general to be perceived as normative, whereas racial minorities with names of religious and ethnic origins may be seen as an inconvenience. This results in experiences of discrimination and ostracism. Individuals with racially and ethnically distinct names often experience a mix of pride and discomfort in association with the mispronunciation of their names. [4]

\section{Contributing to Inequalities}

What we should recognise and talk about is the matter of health inequalities and how the name can be a manifestation of the structural barriers in society. Modern Britain, is a multicultural society with many local communities composed of people with different religion, culture, race and ethnicity. Gender identity is also an important issue. While interacting with patients in many parts of the UK, staff need to have a high level of cultural awareness and sensitivity to the needs of people from different cultural, race or gender backgrounds. However, in many interactions, staff are not trained in cultural awareness and the provider-patient gradient determines how patients are addressed. Inability to pronounce a 'foreign sounding name' is the reality and the norm often is to avoid using the name. I am sure many of us are complicit in this practice.

What starts with difficulty in pronouncing a name, therefore avoiding it- also extends to difficulty in understanding different cultural practices and therefore choosing to passively ignore them. This is a major source of discordant views, that distort the development of commonly shared information, altering perceptions of clinical reality and leads to deterioration of patient experience and outcomes. [5] In such scenarios, the healthcare professional (HCP - being the dominant party) often moulds patient responses and findings into recognisable, manageable patterns within the context of clinical practice. The HCP also determines which portions of the material will be regarded as significant, and this decision is often made unilaterally, independent of the patient's views. Such views may be further biased by the HCP's personal background, values, and social class. In addition, formal training, instruction and certification in medical methodology creates a sense of correctness, authority, and superiority in which "the doctor knows best." These circumstances can lead to a situation in which patient views are overlooked or excluded as invalid concerns. Failure to recognise this issue can block the HCP's ability to consider the patient's views and role in the illness process.

This phenomenon also affects professionals themselves. Esmail and Everington showed clearly how a western sounding name attached to identical applications leads to a significantly higher probability of success in securing interviews. [6] Therefore, it is not surprising that almost a third of immigrant professionals arriving into the United States change their names to more American 
sounding ones, [7] leading to a $50 \%$ higher chance of securing employment.

\section{What is the solution?}

Getting the pronunciation of somebody's name correct (or at least trying to) is important. People often wave through that initial awkward part of an encounter, simply because they've given up hope that others are going to get it right. They wave away the mispronunciations because they've learned to accept that one is not going to invest the few seconds that it will take to pronounce it correctly. But they do care, and it is very important to them. Not taking the time to learn the pronunciation of someone's name sends a powerful message that one is not important or worthy of due respect. The process of 'Westernization' is undertaken because names (therefore such people) are deemed foreign, difficult, and inferior. [8] An emphatic demonstration of exclusion and othering. Conversely, taking the time to try to learn the proper pronunciation of a name suggests that one is being listened to and that one's relationship is important.

Merely recognising and describing the issue of distortion of names and the underlying power gradient and its impact on outcomes is the first step, but not enough. Most importantly, first names play a significant role in determining social status/ranks/relationships. A better understanding of the underlying processes can help facilitate interpersonal and intercultural exchange. Each and everyone one in the healthcare profession has a responsibility to accord due respect to colleagues and patients and strive to work from a position of equality. Being aware of the diversity of names, naming systems in different cultures, is the first step in recognising a fellow colleague or patient as an equal and making an effort to pronounce names correctly is a sign of respect. We have a responsibility to ensure that we do this ourselves, encourage colleagues and peers to do the same. For those with 'foreign' or 'difficult to pronounce names' we have a responsibility to help others to learn the correct pronunciation and therein begins our journey to an equal and just society.

So how do you do this best? Here are five tips to help you promote inclusion [9]
- Simply ask the person to pronounce their name for you. This is much less awkward than taking a guess. If you forget or are still unsure, you can ask them to repeat it or remind you of the correct pronunciation.

- Write down the phonetic spelling of names that you are unsure of, and stick these on your desk. When you are taking the register, remember to have these visible. Be sure to share this with cover teachers, too!

- Use an online tool, such as NameShouts, and listen to the pronunciation of names that are new to you. Practice makes perfect.

- Advocate for your colleagues and patients. If you hear another member of staff mispronouncing a name, gently correct them or remind them of the accurate pronunciation.

- Apologise if you realise that you have mispronounced someone's name. Not only does this demonstrate your willingness to acknowledge your error, but it also shows that you value the process of developing positive relationships.

\section{References}

1 August 2021 NK. Minority ethnic staff 'told to adopt Western names' by managers. Health Service Journal. https://www.hsj.co.uk/workforce/minorityethnic-staff-told-to-adopt-western-names-bymanagers/7030644.article (accessed 13 Aug 2021).

2 BAME staff at NHS trust told to use 'Western names'. BBC News. 2021.https://www.bbc.com/news/uk-england58076939 (accessed 13 Aug 2021).

3 The racist practice of mispronouncing names. 2019.https://www.kuow.org/stories/a-roseby-any-other-name-would-not-be-me (accessed 14 Aug 2021).

4 Understanding Name-Based Microaggressions | Psychology Today United Kingdom. https://www.psychologytoday.com/gb/blog/u nderdog-psychology/201909/understandingname-based-microaggressions (accessed 14 Aug 2021).

5 Putsch RW, Joyce M. Dealing with Patients from Other Cultures. In: Walker HK, Hall WD, Hurst JW, eds. Clinical Methods: The History, Physical, and Laboratory Examinations. Boston: : Butterworths 1990. http://www.ncbi.nlm.nih.gov/books/NBK340/ (accessed 13 Aug 2021).

6 Esmail A, Everington S. Racial discrimination 
against doctors from ethnic minorities. $B M J$ 1993;306:691-2.

doi:10.1136/bmj.306.6879.691

7 Bertrand M, Mullainathan S. Are Emily and Greg More Employable Than Lakisha and Jamal? A Field Experiment on Labor Market Discrimination. American Economic Review 2004; 94:991-1013.

doi:10.1257/0002828042002561

8 Payne KE, Philyaw Z, Rabow J, et al. Names: a new dimension of transformation. Race Ethnicity and Education 2018;21:564-71 doi:10.1080/13613324.2016.1248832

9 Why pronouncing students' names correctly is \begin{tabular}{l|lll} 
vital & Tes & News.
\end{tabular} https://www.tes.com/news/why-pronouncingpupils-names-correctly-so-important (accessed 13 Aug 2021). 